\title{
A construção de políticas nacional e supranacional de informação: desafio para os Estados nacionais e blocos regionais
}

\section{Marta Pinheiro Aun}

\section{Resumo}

A partir de um estudo na França como parte do desenvolvimento da tese de doutoramento intitulada " A construção de políticas de informação no cenário de uma sociedade informacional crescentemente globalizada", o presente artigo narra o resultado das entrevistas onde são colocados os desafios para a construção de políticas de informação nos Estados europeus, políticas estas visando a facilitar o acesso destes países na sociedade da informação.

Palavras-chave

Política nacional de informação; União européia; Desenvolvimento de conteúdos; Tecnologias de informação e de comunicação; Sociedade da informação.
INTRODUÇÃO

O presente artigo descreve os resultados parciais de entrevistas realizadas na Europa, sobretudo em Paris, como estudo de campo financiado pela $\mathrm{Ca}$ pes, acerca da construção de políticas de informação no cenário de uma sociedade crescentemente globalizada e que integrará minha tese de doutorado.

Devido à desativação de órgãos europeus responsáveis em assessorar os governos na construção de políticas de informação, os entrevistados foram selecionados pela proximidade ou atuação nos atuais programas que visam a estabelecer ações para a entrada dos países europeus na sociedade de informação.

Estas entrevistas foram realizadas no período de janeiro a abril de 1999, e o resultado final será apresentado na conclusão da tese com defesa prevista para março de 2000.

\section{POLÍTICA DE INFORMAÇÃO - PANORAMA EUROPEU}

Hoje, quando se faz referência às políticas de informação, sobretudo nos países europeus, não há como se afirmar se determinado país está construindo ou elaborando uma política nacional de informação. O que os governos têm buscado, com programas e decisões públicas, é garantir a participação do país na sociedade da informação. Assim, os problemas referentes à informação estão sendo tratados por duas categorias: o grupo preocupado com o lado que chamaremos de mate- rial, direcionado para a difusão de materiais informáticos, visando ao estabelecimento de redes informacionais e ao grupo que se ocupa de problemas sociais e culturais ligados à informação, voltado então para o domínio imaterial, refletindo sobre a questão do conteúdo na sociedade da informação.

Os programas direcionados para a função material da informação têm sido os de maior empenho por parte dos governos e que têm contado com maiores orçamentos, maiores equipes de estudo e, conseqüentemente, maior poder. Yves Lasfargue ${ }^{1}$ afirma, em sua entrevista, que estas duas categorias de grupos, ao nível da União Européia, representam duas direções de programas e trabalhos: a primeira, que se intitula DGXIII, é a que se ocupa do aspecto material da informação.

A direção DGXIII libera, há mais de dez anos, um grande orçamento na difusão de materiais informáticos. A segunda direção, que se chama DGV, ocupada com aspectos socioculturais da informação, contou, até então, com orçamentos menores e poucos estudos e implementações. Mas, segundo Lasfargue, este panorama tem mudado com a intensidade de reflexões sobre a sociedade da informação e seus problemas socioculturais. Desde 1995, quando se começou a discutir o conceito de sociedade da informação na Europa, o DG V tem se fortalecido, enquanto o DG XIII, por dedicar-se essencialmente à difusão de materiais europeus, tem perdido um pouco de sua grandeza pela difusão maciça de materiais americanos e japoneses, fican- 
do concentrado no problema da capacidade européia de igualar-se neste mercado.

Jean-Noël Tronc ${ }^{2}$ acredita que os países que tenham já uma forte tradição tecnológica evidentemente terão a liderança da construção política para a sociedade da informação na União Européia e, assim sendo, fatalmente irão dirigir os outros. Embora sua ênfase esteja no aspecto tecnológico, acrescenta que o desenvolvimento de redes informacionais só será pertinente nos modelos que possibilitem uso e proveito social e econômico. Citando a França como modelo de tradição tecnológica, inclusive em tecnologia de informação e de comunicação, exemplifica com o Minitel, que embora considere uma rede já ultrapassada e condenada ao desaparecimento, continua ainda em pleno uso, representando um lucro de 15 bilhões de francos ao ano, com 15 anos de uso intensivo e com milhões de usuários.

A mobilização européia para a sociedade da informação, mediante a implementação de políticas de informação, segundo Tronc, é na verdade fruto de iniciativa mais abrangente por parte dos governos dos países membros do que da própria Comunidade Européia.

\section{MERCADO, ESTADO E POLÍTICA DE INFORMAÇÃO}

Toda a Europa, com destaque para a França, Alemanha e Reino Unido, vive um processo de conscientização da necessidade do estabelecimento de uma política de informação que objetive colocar à disposição do maior número possível de cidadãos as informações governamentais, jurídicas, sociais, culturais, econômicas. Entretanto, segundo Queau $^{3}$, a visão dos governos acerca da necessidade e vontade de se construir uma política de informação mais complexa ainda não se apresenta com diretrizes definidas e explicitadas. Para ele, em matéria de política de informação, seu refinamento com clareza de aspectos como conteúdo, tarifação, para se dizer que existe, ainda se encontra em nível de questionamento e discussões.

A ausência da explicitação política no campo da informação tem, segundo Du
Castel ${ }^{4}$, de ser observada a partir de um problema duplo de transformação: a do mercado e a do Estado, que redunda em mudanças no campo da informação, quando esta deixa de ser de controle estatal, como o era no pósguerra, para aos poucos ir se tornando privada, em uma estrutura nova, iniciada pela televisão e que vai passando de monopólio estatal para um hibridismo de público e privado, o mesmo acontecendo à imprensa.

As transformações do mercado, em nível mundial, atingem as economias dos Estados pelos processos de privatizações e da desregulamentação do mercado, limitando a participação dos Estados ao fornecimento de tradicionais bens públicos e à tarefa de regulamentar. Tais processos atingem o campo informacional por meio das Tecnologias de Informação e Comunicação (TICs), cuja valorização, nas duas últimas décadas, atinge o seu ápice com o surgimento das infovias de informação, ou redes, com destaque todo especial para a Internet. O destaque do aspecto tecnológico desestabiliza o processo de construção de políticas de informação, gerando, segundo opinião da maioria dos entrevistados, uma falta de consciência dos valores de conteúdo informacional, com olhar sociocultural. Para Du Castel, é necessário que o Estado "lance um olhar político sobre os problemas técnicos". E ainda acrescenta:

"Tem-se que olhar se o maior privilégio é para a infra-estrutura pois parece que é só isto que domina: o desenvolvimento de infra-estrutura que é hoje determinado pela política de desregulação, pela política de concorrência. A abertura à concorrência, que hoje domina na Europa, absorve então todos os problemas de redes de comunicação. Desta maneira, é o mercado que domina no desenvolvimento de tecnologias de informação e comunicação.

Assim, se não temos políticas explicitadas, um olhar político sobre os problemas técnicos, tudo fica sob o controle do mercado. Não se trata de as novas tecnologias representarem um problema, mas é necessário definição política na escolha dessas tecnologias, seu emprego, uso, sua colocação geográfica etc. Tecnologias para comunicarem o quê, qual o conteúdo, evitando que se transforme a informação unicamente em mercadoria."

Já Dagnaud 5 acredita que a idéia de se abandonar ou deixar os setores de regulação ao critério só do mercado não é adotada pela França. Para ela, a França não pensa a sociedade de informação, tomada em toda a sua globalidade, inteiramente presa às forças de mercado, considerando mesmo este pensamento de total submissão, um fanatismo. Chambaud ${ }^{6}$ e Confland ${ }^{7}$ concordam, reconhecendo que existam especificidades de interesses do mercado e outros interesses ligados ao exercício de soberania do Estado. Já Rauzier $^{8}$, Le Coadic ${ }^{9}$ e Du Castel acreditam em um desengajamento do poder público francês no plano da informação ou da política de informação, pois a maioria das instituições administrativas que possuíam o encargo da definição aconselhamento e implementação destas políticas junto ao governo foi desaparecendo a partir de 1986. Não mais existindo tais estruturas, acreditam mesmo na ausência de uma vontade política real que venha a assegurar a implementação de uma política nacional de informação. A seu ver, a responsabilidade ficaria ao cargo do movimento concorrencial, que em economias liberais tem tendido a valorizar o desenvolvimento de tecnologias, desengajando os Estados europeus da construção de uma política de informação. Segundo Rauzier este movimento ainda irá continuar, não se tratando de um contra-senso exclusivo da política de informação, ou de uma política de conteúdo de informação, exigindose, para equilíbrio, maior nível de consciência nacional por parte dos diferentes governos europeus.

As diferentes tendências como demanda social, demanda cultural, progresso tecnológico em todas as épocas coexistiram, sendo que sempre houve 
a sobreposição de uma que se colocava mais forte por estar aliada à vontade política, sustentando uma ideologia que se refletia em uma política explicitada. Mas hoje, segundo opinião da maioria dos entrevistados, o novo cenário mundial, de força internacional, nos apresenta fortes movimentos de transição onde a Europa, como o resto do mundo, vive um liberalismo que, segundo, Du Castel, desestabiliza os governos ao ponto de parecer que os dirigentes estejam agindo somente à ordem da economia. "Não parece haver a originalidade e a vontade de se criar políticas que correspondam à demanda social, ou melhor, sociocultural, numa adequação de governo à sociedade". Para ele, políticas sob a lógica de mercados são políticas que não abordarão problemas informacionais de interesse da população. Assim, problemas sociais, como desemprego ou exclusão informacional, tornam-se estranhos a estes domínios, e o mercado, naturalmente, não irá cuidar. Du Castel, Lasfargue, Queau e Cacaly ${ }^{10}$ reconhecem que a Europa vive uma época de grande transição, com dificuldade de coordenação, em que o ritmo de decisões, se não lento, é por se fazer prudente, espelhando a insegurança, sobretudo para a criação de uma política consistente para a informação.

Alguns dos problemas advindos da demanda social, retratando as especificidades culturais e sociais de cada país, dificilmente seriam resolvidos pelo mercado. Para estes casos, a falta de uma política que se volte para o desenvolvimento sociocultural, preocupada com os aspectos de conteúdo e não somente com os aspectos tecnológicos, ignora, como bem assinalou Queau, em sua entrevista, que o mercado em si não é prioridade, mas um meio, não passando de um instrumento para se atingir ou se realizar algo.

Rauzier assinala que a competição econômica, evidente e concreta, é que induz todos os países a se defenderem de um atraso tecnológico, obrigando-os a estar à frente das tecnologias e a dependerem do avanço dos outros. A liderança dos EUA alastrase nas instâncias da Comunidade Européia, parecendo direcionar a todos a se ocuparem dos instrumentos tecnológicos, em um aprisionamento coletivo neste movimento.

A construção de uma política de informação implica o que é verdadeiramente prioritário: o desenvolvimento da sociedade de forma justa e democrática, e assim pensando Queau pontua:

"Acho que a sociedade da informação é que é a prioridade, e não o mercado, porque representa a livre circulação de idéias. O mercado foi criado pelo capitalismo para a circulação e a livre concorrência. Não foi criado para o dinheiro, e sim para a liberdade."

O desenvolvimento de uma infra-estrutura tecnológica é condição sine qua non para que se tenha acesso à sociedade da informação. Porém, precisase pensar o nível de prioridade da infra-estrutura na construção de políticas e programas informacionais. $O$ desenvolvimento da infra-estrutura é o que hoje domina os programas europeus para entrada na sociedade da informação. E o desenvolvimento desta infra-estrutura está determinado pela política de desregulação e pela concorrência. Para Du Castel, é o mercado que domina o desenvolvimento de tecnologias. Não se trata, portanto, de as infovias serem um problema, trata-se da homogeneização mundial ao se tratar o processo, ou seja, a preocupação dos entrevistados acerca do aspecto tecnológico é a ausência de análise crítica no estabelecimento desta infra-estrutura. Que tecnologia se deve adotar? Em que situações? Em quais espaços, sob que condições ? O que é considerado mais importante ?... Para se atender a quais conteúdos selecionados? Que técnicas de redes, de terminais devem ser identificados para a solução de problemas e necessidades diferenciadas? E o que é mais destacado, identificar quais informações se farão circular por redes e por quais caminhos, concentrandose mais na sua seleção que somente no aspecto de difusão. Em relação a estes caminhos, os entrevistados foram unânimes em condenar o trajeto percorrido pelas informações nas re- des, bem como nas comunicações telefônicas. Uma informação saída do Brasil em direção ao Uruguai, ou da França em direção ao Reino Unido, passa obrigatoriamente pelos Estados Unidos. Assim, sugere-se a criação de estruturas regionais que possibilitem aos blocos como o Mercosul e a União Européia ter formas de acesso e comunicação mais independentes.

\section{TICs E CONSTRUÇÃO POLÍTICA}

O surgimento de novas tecnologias, em todo o decorrer histórico, costuma acarretar duas vertentes: a dos que querem se apropriar destas tecnologias e a do controle, do represamento do uso que possa vir a ser feito destas tecnologias. Em sua imprevisibilidade, novas tecnologias provocam uma evolução obrigatória aos conteúdos já existentes. Um exemplo atual foi dado por Cacaly em relação à Internet. Se a analisamos, diz ele, há o interesse comercial de sua utilização, de uma padronização de sua utilização, interesses de mercado e, por outro lado, sua utilização por parte das universidades, pesquisadores e estudantes que estão sempre a questionar o seu conteúdo informacional. Dentre os que querem se apropriar destas tecnologias informacionais, tanto o setor privado, quanto os governos dos Estados têm em vista o desenvolvimento do comércio eletrônico. Neste setor as TICs possibilitaram indiscutivelmente 0 desenvolvimento de novas riquezas e de novos setores que criaram novos empregos. Segundo dados fornecidos por Tronc, no ano de 1998 o PNB francês (Produto Nacional Bruto) cresceu a cota de $0,5 \%$ e unicamente devido às TICs e ao comércio eletrônico.

Quando se perguntou se havia uma distância entre o desenvolvimento das TICs e o estabelecimento de uma política de informação, a maior parte dos entrevistados respondeu de forma bastante imprecisa: "Não verdadeiramente". Justificaram com a fase de transição e de adaptação às exigências do mercado mundial. Somente Rauzier e Le Coadic foram categóricos em afirmar que esta distância se tornava uma dificuldade para o estabelecimento da política. Já Queau e Chambaud argumentaram que a evidência é de se estabelecer políticas de forma geral. Que 
esta dificuldade advém da necessidade de se refletir sobre as prioridades a serem desenvolvidas, sobre os meios para atingir estas prioridades, na forma de estabelecê-las e implementálas e de definir suas estruturas, o que é sempre dificultado pela oposição de interesses. A oposição de interesses do setor privado acaba por dificultar aos Estados e aos dirigentes no estabelecimento destas prioridades. E nesta linha de pensamento Chambaud completa:

"As TICs são só instrumentos, não mais do que isto, e, se estão à disposição, é necessário que as apliquemos, utilizando políticas que utilizem tecnologias que estão disponíveis no mercado, o que não significa uma ausência de seleção e de reflexão sobre estas tecnologias".

Escolher a partir das tecnologias é um erro, deve-se julgar o seu emprego. Assim considera que, no aspecto tecnológico, o risco hoje vem da Internet, por intermédio de mudanças muito radicais por ela trazidas, por tratar-se de uma rede mundial, que veicula um certo número de valores de mercado, que são na verdade valores econômicos. O risco está na qualificação e análise do discurso que caracteriza a rede como representação da democracia, liberdade, individualismo e na verdade por trás se encontram interesses econômicos onde a lei é o lucro. Isso, segundo Chambaud, conduz a um risco de colonização muito forte por parte de operadores anglo-saxões, bastante poderosos e pouco europeus ou latinos, neste domínio. "É importante que a Europa crie resistência a esta influência unilateral, e a maneira de se resistir não é a de impedir, mas de se bater por um equilíbrio de monopólios".

Para a construção de políticas de informação, é fundamental que se pense no desenvolvimento e implementação das TICs. Mas, uma política que vise somente à infra-estrutura, com os entrevistados se colocando em acordo que as políticas atuais privilegiam em excesso a construção de infra-estrutu- ra de redes, torna-se uma política parcial. Política de infra-estrutura, segundo Rauzier, é uma linha de política tecnológica, não podendo ser caracterizada como política científica e muito menos ainda como política de informação. O desenvolvimento de bancos de dados, de cd-roms e, agora de infovias como a Internet são ainda categorias sobre as quais não se conhecem todo os dados, obrigando a se olhar com cautela, para que se evite despender orçamentos excessivos na construção e implementação de tecnologias que venham a se tornar aberrações (Confland). Para Rauzier construir rotas e infovias é construir infra-estruturas que só terão significado político se justificadas a um circuito, com finalidade própria de conduzir informações selecionadas e dirigidas por interesses sociocientífico-culturais.

\section{POLÍTICA DE INFORMAÇÃO, POLÍTICA SOCIOCULTURAL}

Na França, como na Alemanha, os primeiros-ministros assumiram pessoalmente a direção da política de informação, mediante a implementação de programas visando à entrada destes países na sociedade da informação. $\mathrm{Na}$ entrevista com o conselheiro do primeiro ministro francês Lionel Jospin, o senhor Tronc afirmou que o interesse do primeiro-ministro de se engajar pessoalmente neste programa não seria de cunho econômico, embora este aspecto motive parte do campo de trabalho, mas que na verdade é o campo político-cultural que tem a prioridade, pois o Estado precisa se mobilizar por defender os interesses culturais de um país com tal força de tradição neste campo, como é a França. Assim, o programa governamental francês intitulado Programme d'Action Gouvernemental pour la Société de I'Information (PAGSI), objetiva, segundo o Conselheiro, ajudar o desenvolvimento francês, familiarizando toda a população com as novas tecnologias de informação por meio da modificação do sistema educacional, local onde se coloca a questão da reprodução das desigualdades, cabendo então ao Estado a difusão, disseminação, ajudando aos diferentes atores na criação cultural. E acrescenta que, se o Estado assim não agir, estará atuando com omissão. O programa tem o apoio do senhor Queau, embora o considere inconsistente para o domínio sociocultural por deixar várias questões em aberto em relação a financiamentos, campos privilegiados, formação de docentes, as barreiras psicológicas geradas pela tecnologia e mesmo a vultosidade do programa, segundo sua opinião, torna-o de difícil concretização.

Lasfargue aponta outros problemas no programa que, para ele, não determina quem, quando e como se irá utilizar todas as máquinas numeralizadas e a colocação de problemas como distância e proximidade. Para ele, países de dimensões tão gigantescas como o Brasil teriam necessidade de serem mais eletronizados que a França, por exemplo, por se tratar de um país de menores dimensões, onde o telefone em certas circunstâncias é suficiente para uma comunicação eficaz. Destaca também a aceitação da sedução das novas TICs, achando desnecessário que todas as formas de comunicação sejam por via eletrônica. Lembra que toda a tecnologia nova costumava exigir um trabalho de convencimento por parte das empresas, o que não tem acontecido, por exemplo, com os microcomputadores e telefones celulares e que são tecnologias que estão sendo adquiridas tanto por empresas, como meio de produção, como por pessoas, como meio de atualização. Já Du Castel afirma que este programa não traduz uma vontade de política sociocultural ao ponto de se poder dizer tratarse de uma política educativa. Para ele, o que se sente por parte do governo francês é uma tendência a introduzir uma prática de uso de novas tecnologias no ensino, na rede de ensino, mas que não passa de uma distribuição de computadores às escolas, muito mais que uma preocupação pela educação que tratará de preparar os franceses para o uso consciente às suas necessidades. Que a prática do uso destas tecnologias corresponda às experiências destas pessoas, estando a seu serviço, e isto não é evidente neste programa.

\section{IMEDIATISMO, INCONSISTÊNCIA OU FALTA DE POLÍTICA}

Em sua maioria, as entrevistas realizadas confirmaram a ausência atual de 
uma política nacional de informação na França. Todos concordam que o governo tem tido ações, como o PAGSI, mas que não é suficiente para que a França, como os demais países europeus, tenham sua individualidade e garantam sua cultura informacional. Para Queau, embora ele aprove a atitude do primeiro ministro em lançar este programa, visando à entrada da França na sociedade da informação, o governo enfrentará grande dificuldade em efetivá-lo. "Acho que há uma distância muito grande entre este programa e a ação efetiva".

O governo francês justifica este programa por meio do discurso do atraso:

"Logo que o primeiro ministro Lionel Jospin formou o seu governo em 1997 apoiado pela esquerda, a situação da França era paradoxal. Era uma situação marcada por um atraso indiscutível que acaba de ser colocado em discussão e aceitação no domínio tecnológico, atraso então na utilização de tecnologias de informação pelo sistema educativo, um atraso então na presença da França na Internet e da utilização destas tecnologias pelas pequenas e médias empresas e um atraso, enfim, na utilização destas tecnologias pelos serviços do Estado, pela administração e sobretudo na difusão da informação pública." (Tronc)

Nossos entrevistados são unânimes em dizer que o discurso do atraso já é um chavão discursivo, pois fala-se sempre deste atraso francês, em um país que é a quarta potência mundial, ao que Rauzier acrescenta que construir uma política de informação no seu sentido mais amplo não é para se recuperar atraso, isto é insuficiente. "Necessário mas verdadeiramente insuficiente."

Para Du Castel e Queau, a ausência de uma política informacional, substituída por ações e programas a curto termo, nada mais é que o reflexo de uma cultura de desregulamentação que enfraquece o Estado ao nível de realizações. Para Du Castel esta cultura de desregulamentação é advinda dos Es- tados Unidos e tocou planos profundos, afetando a possibilidade de construção de políticas nacionais coerentes.

"Neste contexto as grandes empresas lucrativas aos cofres públicos vão sendo privatizadas e o Estado se redime de se colocar em oposição a esta política de origem anglo-saxônica".

Nesta mesma linha de pensamento, Cacaly acrescenta:

"Não há concretização, não há... são bloqueios externos e o que é mais grave é que não há uma vontade política que se traduza por um meio, um fio condutor que uma empresa como a nossa ${ }^{11}$ possa se beneficiar, se engajar neste programa. O discurso de Jospin não parece corresponder ao que eles vão fazer. O seu discurso à Universidade de Hourtin, em agosto de 1997, responde ao discurso de Al Gore, só que com cinco anos de atraso."

Para Le Coadic, Cacaly e Rauzier, o imediatismo das ações políticas governamentais francesas se inicia em 1986 com o desmantelamento dos organismos operacionais que se ocupavam em assessorar o governo na construção da política nacional de informação. O desaparecimento destas direções não Ihes parece um processo de destruição criadora, pois não foram substituídas. Além do mais, eles consideram que a maior dificuldade vem do desconhecimento do conteúdo destas instituições. Assim, iniciada a década de 90 , há cada vez menos intervenção do Estado em todos os domínios, o que ocorre também no domínio da informação (Lasfargue). Apesar da interferência atual do governo em referência à questão da Internet, para colocá-la no interior do serviço público, o que Lasfargue considera um avanço pelo papel motor que o serviço público exerce na França, ele interfere muito pouco nas empresas, o que acontecia habitualmente há cinco anos.

\section{DESAFIOS À CONSTRUÇÃO DE UMA POLÍTICA DE INFORMAÇÃO}

A construção de uma política de informação, no seu sentido mais amplo, é hoje, sem sombra de dúvidas, um desafio para todos os Estados. Os entre- vistados centram este desafio no movimento liberal que assola o mundo e, como não poderia deixar de ser, fez o seu domínio na Europa. A Europa, então com fortes tradições culturais, depara-se com a invasão ideológica americana, que se faz mais dominante nos pontos que caracterizam a sociedade da informação.

"Com a sociedade da informação, deparamo-nos com um desafio ideológico, um desafio de conceito e ainda não temos na Europa, nem na França, um pensamento estruturado para este problema." (Queau)

Para Cacaly, o problema maior hoje a ser enfrentado pelos Estados no sentido da construção de políticas é a ênfase liberal, que deixa os Estados completamente perturbados, desestabilizados na sociedade da informação, afetando tudo que já estava colocado e protegido em diferentes planos jurídicos. O posicionamento ideológico europeu e, individualmente, de cada Estado é a condição primordial para se solucionarem problemas e vencer os desafios da sociedade da informação. A partir daí, pode-se melhor estabelecer as estratégias necessárias para se vencer os diferentes desafios à construção de políticas de informação.

O desafio mais importante, segundo os entrevistados, é o de salvaguardar a própria cultura, e este ponto será mais difícil para os países cuja língua não seja o inglês, ou que não tenham o inglês como segundo idioma. A própria União Européia adotou o inglês como idioma oficial da comunidade. $E$, como sabemos, a língua é a base da cultura. A França, de forte tradição cultural, principalmente no campo cinematográfico, tem encontrado dificuldades, segundo depoimento de Lasfargue, de colocar em rede seus filmes, suas canções, pela limitação da comunicação lingüística. E é este o grande problema da Europa, segundo Chambaud, ter uma estrutura de múltiplas línguas, diferentes culturas, dificultando uma ação rápida na sua divulgação. Este é um desafio ligado diretamente à questão de conteúdo. E o conteúdo na sociedade da informação não pode ser uniforme. Nas palavras de Confland: 
"É necessário defender a idéia de uma independência de conteúdo, de um modelo cultural que não seja só o dos americanos, que o Estado aplique sua dose de intervencionismo, uma dose de voluntariedade, que a qualquer oposição americana, a independência cultural seja garantida."

Todos os entrevistados foram unânimes em afirmar que, embora os governos europeus, com maior referência ao governo francês, estejam se empenhando para a colocação de seus países na sociedade da informação, não há uma consciência clara da importância do conteúdo no estabelecimento de programas e ações para a sociedade da informação. Não existe uma intervenção forte que justifique esta preocupação. Para Lasfargue o problema é distribuição de financiamentos e de orçamentos. Segundo sua opinião, os aspectos culturais ou de conteúdo têm caráter imaterial, e é muito complicado se colocar dinheiro público no domínio imaterial. Para se criar conteúdo, é necessário um esforço econômico que subvencione esta criação. $\mathrm{E}$ quando se coloca dinheiro em conteúdo, ele não é claramente visualizado, e é este o problema. Mas é aí, ainda segundo ele, que os americanos, já com domínio do mercado, inibem as iniciativas dos Estados, pois, quando estes exportam um produto, este, subvencionado, entra em concorrência internacional já com preços imbatíveis no mercado. Um exemplo claro dado por ele é sobre o desenvolvimento de cdrom. Um cd-rom americano, traduzido para o francês, custa, desde a sua criação, um milhão de francos. Já um cdrom fabricado com tecnologia francesa custará a seus idealizadores e fabricantes dez milhões de francos. Assim fica evidente a dificuldade de se fabricar e a facilidade de se consumir, e é neste consumo que se enraíza a ideologia anglo-saxônica. Ainda é ele que sinaliza que somente a Alemanha, França e Itália estão se esforçando pela criação de conteúdos. Os outros países europeus estão só consumindo e, o que é pior, consumindo conteúdo americano e japonês e refutando a aquisição de conteúdo europeu. Confland adverte que, mesmo dentro do liberalismo, sendo um liberalismo europeu, os Estados devem propor- cionar um número de garantias à cultura, preservando os aspectos culturais e difundindo-os mediante conteúdo genuinamente europeu. Para ele, isto de forma alguma impedirá que os instrumentos tecnológicos e talvez mesmo culturais sejam mais utilizados, mesmo sendo os americanos, o que não deva inibir a criação européia de um conteúdo que lhe seja apropriado. Este domínio, segundo ele, Lasfargue e Polanco ${ }^{12}$ tem se tornado uma realidade complicada para a Europa e é característica da sociedade da informação. $O$ curioso é que o mesmo não se passa em outros setores como o dos telefones, automóveis, trens, alimentos. Mas se passa com a produção de micros, programas, cd-rom.

Retornando à discussão da tecnologia, em oposição ao conteúdo, Chambaud não os coloca como pólos opostos, mas interdependentes e com prioridades diferentes. Para ele, ao se construir uma política de informação, é necessário que se faça uma reflexão sobre o conteúdo e, em seguida, sobre a tecnologia adaptada a este conteúdo, e não no sentido contrário, como se tem feito no governo francês e em outros Estados europeus. A este comentário, é interessante que se ajuntem as idéias de Rauzier, que encontram eco nas seguintes palavras de Lasfargue:

"Então, quando dizemos que o que existe em matéria de política de informação não é importante é porque não está estabelecido um conteúdo nem francês, nem europeu. Os programas desta área tratam de tecnologias e não do conteúdo destas tecnologias. O limite, portanto, para o momento, é que não existe uma política que determine orçamentos e financiamentos referentes à Europa e, sobretudo, referentes à França, para se integrarem realmente à sociedade da informação, criando um conteúdo europeu ou nacional".

O segundo maior desafio é uma conseqüência deste primeiro. Trata-se da aproximação cultural da Europa para que se possa estabelecer uma verdadeira sociedade européia da informação. Lasfargue coloca o problema a partir da concepção das redes européias. Estas, segundo ele, não foram concebidas para tratar a informação eu- ropéia, o que mostra claramente o limite de uma política visando a sociedade da informação. Assim ele pontua:

"As redes são atualmente a parte mais flexível, imaterial; então, o conteúdo é de cada um, portanto, a rede pode e deve ser européia."

Sua preocupação é como se irá construir uma sociedade européia de informação conservando-se as próprias especificidades. A França, com suas características culturais fortes, que conserva e privilegia um certo "culto do original", que não aceita cópias em museus, como os japoneses, enfrenta naturalmente maior resistência nos aspectos da sociedade da informação, onde tudo é numeralizado, onde não existem obras originais. A cópia de um software é tão boa quanto o seu original. Outro ponto levantado por Lasfargue é em relação ao movimento de mundialização. Mesmo sendo a França a quarta potência mundial, cria resistência e tenta não se deixar modelar ou moldar por este movimento. A Alemanha também tem estabelecido seus limites. E ele acrescenta: "Mas a Dinamarca, Holanda, Suécia, se prestam totalmente ao movimento da mundialização, sem jamais terem sido líderes deste movimento".

A aproximação cultural depende da comunicação entre os países. E, nos estudos da União Européia, fica claro que esta comunicação é hoje bastante dependente do uso de tecnologias e que os países membros têm aí níveis de avanço bastante diversificados.

Ao se falar desta dependência da comunicação, chegamos ao terceiro desafio apontado por Rauzier e Lasfargue, que é o limite da sociedade chamada de informação, e toda a concentração na comunicação. Para nossos entrevistados, ambos os termos estão sendo mal colocados. Os instrumentos de comunicação existem e são ferramentas, mas para comunicar o quê? Este é um dos desafios enfrentados pelos diferentes Estados, quase 
sempre que se fala em comunicação em redes, comunicação da sociedade da informação. Segundo Lasfargue, estamos falando sobre a informação numérica que se encontra nos computadores. Volta-se ao problema do conteúdo acrescido do distanciamento de se buscar uma informação:

"Quando nós assim pensamos numa SI visando a uma totalidade onde tudo irá passar por terminais, o cidadão conversará através dos terminais como acontece hoje na Dinamarca. Se passaremos a nos comunicar nesta sociedade por terminais, por computadores, precisamos ainda analisar se assim será necessário, se isto é modernização, se a comunicação somente por vias eletrônicas será eficaz, pois a Europa do Norte já começa a demonstrar um cansaço de tudo isto"

O quarto desafio de certa forma se interliga aos anteriores. Desde a década de 50, cabia aos Estados o controle e regulação das informações. Em meados da década de 90 , o mundo se depara com o fenômeno Internet, que permite a circulação de um volume brutal de informações via redes, sem que ainda se tenham meios de se controlar as fontes que originam estas informações. Dagnaud aponta a Internet como enorme desafio, pela dimensão que representa o assunto, e que torna impossível de ser regulado no âmbito dos Estados, por se tratar de um rede internacional, de tal forma que a ação não pode ser feita senão mediante a cooperação entre os Estados, pois além das fontes informacionais que alimentam a rede, ainda se apresenta uma infinidade de pontos a serem regulados, como, por exemplo: direito do autor, proteção de marcas, proteção de pessoas, da infância, da adolescência.

O quinto desafio preocupa hoje o mundo todo e assombra a Europa. Sobre ele a União Européia apresentou o livro verde: Viver e Trabalhar na sociedade da informação: prioridade da dimensão humana. Este documento retrata as inquietudes do mundo do emprego na era informacional. Uma revolução que exige novas competências e cria a insegurança do desemprego. A política de informação deve refletir sobre este estado de desassos- sego, de sensação constante de incompetência diante das mudanças tão rápidas acarretadas pelo desenvolvimento das TICs. As novas condições de trabalho, o trabalhador em casa ligado a um terminal, a ausência e regulação das novas e diferentes formas de trabalho, onde os trabalhadores perdem seus direitos, pois os sindicatos se encontram limitados na representação das diferentes classes profissionais. Várias profissões desaparecem e novas vão surgindo, exigindo da classe trabalhadora novas competências que as estruturas educacionais não estão suprindo. A profundidade do nível de mudança em torno do trabalho na sociedade da informação tem de ser vista pelas políticas de informação, pois, para Tronc, se no setor de serviços ainda temos uma fraca substituição humana pelas tecnologias informacionais, no setor industrial esta substituição acontece em alta escala. Se hoje o desemprego é questão prioritária na Europa e se é espelho de uma nova sociedade que se apresenta, as políticas representativas desta sociedade terão como desafio este grande problema.

Um sexto desafio se refere à regulamentação na sociedade de informação. Dagnaud, Du Castel, Polanco, Tronc e Confland são os mais preocupados com este aspecto. Para Du Castel, o que falta neste momento na França e em outros países da Europa é uma reflexão sobre um outro modo de regulamentação no lugar dos que já estão instalados. Ele e Polanco questionam como os Estados irão regular estes domínios que são neste momento concorrenciais, imateriais e que, portanto, as formas de regulação já instaladas, vêm atendendo a interesses de mercado e não refletem uma política cultural ou social no campo da informação e da comunicação. Para Du Castel, infelizmente não é esta hoje a orientação da política fundamental, o que influencia diretamente a construção de uma política de informação.

"Hoje não se faz outro tipo de regulação que não seja de intenção econômica. Quando temos declarações diretas contra os programas de pederafilia e de violência que correm soltos na Internet, na verdade não passam de declarações, discursos governamentais que não são explicitados numa política real que dê conta de regular esta situação."

Para ele, neste sentido, o governo pode fazer o discurso do atraso. $O$ atraso da falta de reflexão sobre as novas tecnologias e a sociedade: "A questão política se coloca em atraso em relação à tecnologia. A tecnologia avança e a política não reflete sobre este avanço."

Para Dagnaud, que é uma especialista do assunto, e Tronc, os modelos de regulação como eles existem hoje funcionam bem para as mídias tradicionais, rádio, televisão. Mas não existe a definição de um modelo de regulação que possa controlar a Internet, nem as redes em linha, onde as informações veiculam "de maneira mais frouxa, mais aberta". Ambos concordam que os modelos tradicionais de regulamentação, feito pelos Estados ou por instância, independentes de regulação como existem o Conseil Supérieur d'Audiovisuel (CSA), a Autorité de Regulation des Télecommunications (ART) ou Commission Nationale de l'informatique et des Libertés (CNIL) não são mais apropriadas para os veículos informacionais da sociedade de informação. Assim, concordam que talvez o sistema de co-regulação seja o mais adequado e mais ágil para se regular os possíveis desvios informacionais da Internet.

Para Rauzier e Du Castel, na construção de uma política de informação, hoje o desafio de regulamentação se faz muito mais pelo desaparecimento de órgãos como MIDIST ${ }^{13}, \mathrm{DBMIST}^{14}$, $\mathrm{DIST}^{15}$, que existiam na França exatamente para analisar as informações em conteúdos e qualidade, bem como não permitir que estas informações penetrassem de maneira a danificar a sociedade.

Segundo Tronc, tudo que diz respeito à regulação na sociedade de informação é prioridade governamental, constituindo uma das seis linhas prioritárias do PAGSI: "Promover a emergência de uma regulação eficaz e de um quadro protetor para as novas redes informacionais". A regulação visa à proteção da infância e adolescência, dos consumidores, da assinatura eletrônica, dos criadores mediante a proteção dos direitos autorais, da propriedade intelectu- 
al, a proteção dos usuários e fazer frente à criminalidade na informática, além de outras problemáticas que advenham do sistema de redes.

\section{ACESSO E EXCLUSÃO NA SOCIEDADE DE INFORMAÇÃO, O DESAFIO DO ENGAJAMENTO}

Para Confland, a sociedade de informação acarreta em si a possibilidade de se alcançar ou saltar etapas, se bem aproveitada. Em suas palavras:

"Ter acesso à sociedade de informação implica saber ganhar tempo, saltar gerações de conhecimentos, sabendo fazer uso das tecnologias participativas, interativas, que permitam novos modelos de desenvolvimento, onde se possa ultrapassar caminhos que outros mais lentamente percorreram. É saber ultrapassar as informações básicas para se atingir novo grau de conhecimento. Foram estes os passos de oportunidade oferecidos pela sociedade de informação que a Coréia do Sul bem soube aproveitar".

Ainda falando das oportunidades, destaca o encurtamento de espaços, de distâncias e de tempo. Regiões longínquas do universo, se munidas de telefonia, hoje têm acesso às redes e a tudo que elas proporcionam.

Já Rauzier e Du Castel vêm alertar que os governos têm de estar atentos ao acesso nesta sociedade da informação. Segundo eles, para se ter acesso, é necessário identificar-se com a informação, que então deverá refletir as necessidades, preocupações e interesses das pessoas, não se podendo permitir que corram somente pelo lado do mercado.

Ter acesso é saber analisar, selecionar, filtrar, para então absorver a informação e aí poder transformá-la em conhecimento. Para se realizar na sociedade de informação, saber absorver, ou queimar etapas como destacou Confland exige-se nível de competência e capacitação muito maiores dos que foram exigidos na entrada da era industrial, quando, como lembrou Queau, a população mundial teve de se alfabetizar. Além do mais, como destaca Du Castel, o acesso às redes é um investimento caro, adquirir um microcomputador, fazer uma inscrição na Internet e, assim mesmo, para fazer uso, pela maior parte, somente da informação básica.

Assim, a grande preocupação do Grupo de Experts de Alto Nível, em seu relatório final sobre a "Construção da sociedade européia de informação para todos" é de uma Europa a duas velocidades, onde uma minoria, já chamada de inforicos ou globoricos por Queau, terá acesso, e uma maioria, os infopobres ou globopobres serão excluídos, da maneira mais drástica que na era anterior.

Em relação a esta preocupação, o grupo de entrevistados se divide. Du Castel, Rauzier e Polanco aderem a este pensamento. Confland, Tronc, Chambaud, Lasfargue e Le Coadic consideram que jamais se chegará a uma soma positiva ou negativa para este problema. Lasfargue considera que sempre houve e sempre haverá diferenças, só que, pelo próprio desconhecimento de sociedade da informação esta diferença torna-se difícil de ser nomeada. A este pensamento Confland acrescenta:

"O que podemos constatar é que em todas as épocas sempre existiu ricos e pobres, excluídos e inclusos; quando olhamos o mundo e suas diferenças de países pelo desenvolvimento, evidentemente vamos também constatar estas diferenças na sociedade de informação. A alfabetização em porcentagem mundial não tem progredido. Este é um dado grave. A fome também não regrediu. Portanto, com estes dados básicos, então o melhor a se observar em políticas é que os países desenvolvidos é que estão dirigindo a sociedade da informação e que, para os países em desenvolvimento, a diferença poderá ainda ser maior que em outras eras, devido ao grau de exigências e competências exigidos para se integrar à nova era da Informação."

Mas o ponto de acordo entre os entrevistados é a questão das novas exigências educacionais e de capacitação para se integrar à sociedade da informação. O caráter entrópico das informações nas redes exige qualificação para se filtrar e extrair informação necessária em tempo hábil. A capacitação dos cidadãos é um problema para os Estados, e o tratamento a ser dado às informações eletrônicas também. Se as informações não forem organizadas e tratadas e a veiculação normalizada, o discurso de que a sociedade da informação encurta tempo e espaço poderá cair no vazio.

\section{CONCLUSÃO}

A dimensão econômica é hoje o grande agente monopolizador dos Estados. A globalização dos mercados e sua liberalização transforma os Estados Nacionais e os desestabiliza. As políticas econômicas são a pauta dos governos, e, paralela a elas, por parte dos governos dos países mais avançados e fortalecidos econômica e tecnologicamente, surge a necessidade de um engajamento na sociedade de informação. Os países se preocupam com a construção política de sua área informacional, visando à participação neste novo cenário que é crescente e internacionalmente globalizado pelo maior fenômeno da década: as redes de informação e comunicação.

O resultado das entrevistas deste estudo de campo mostra que ainda existe imprevisibilidade para que se possa afirmar que os países europeus estejam construindo novas políticas de informação diferentes das décadas do pós-guerra, quando refletiam o avanço e os objetivos da área científica e tecnológica. Fica clara a vontade e o interesse voltados para o setor, mas a coordenação do novo parece inibir os dirigentes governamentais em explicitar estas políticas. Todos enxergam as grandes possibilidades acarretadas por esta nova sociedade, mas parecem estar amarrados a um emaranhado de desafios que dificulta o estabelecimento de prioridades.

É ponto pacífico que a liderança da sociedade da informação tem ficado a cargo dos países que já têm o desenvolvimento e domínio tecnológico exigidos e a preocupação dos entrevistados é em relação à forma de se fazer esta liderança. Conscientes que os Estados Unidos têm ocupado o lugar de "primeiro da classe", preocupam-se com a sua forma de lidar com a área informacional, deixando-a nas mãos do mercado. Usando o discurso do atraso ou do desemprego, o investi- 
mento financeiro, todos os orçamentos têm se concentrado no aspecto tecnológico, no caráter material da área de informação, com toda a força se concentrando no desenvolvimento de infraestrutura, tecnologia informacional e comércio eletrônico.

Os entrevistados reconhecem a importância do estabelecimento de uma potente infra-estrutura e da capacidade de gerar empregos e dividendos pelo comércio eletrônico, mas estão conscientes de que a concentração neste aspecto cria a desestabilização nacional pela ameaça do empacotamento cultural e suas especificidades européias. Com a concentração na comunicação e difusão de informações pela orientação mercadológica, estas especificidades não serão cuidadas, e a absorção de informações neste novo espaço eletronizado fica então claramente limitada. A concentração na tec-

\section{The construction of national and supranational information policies: challenges for individual nations and regional blocs}

\begin{abstract}
After a field study in France as part of the development a the doctor teses intitted "The construction a information policies in a globalized informational society." This article states ten interviews where the chalenges to construct information policy in the european states policies which gols is to facilitate the acess of these countries into the information society.
\end{abstract}

\section{Keywords}

National information policy; European union; Contents development; Information and communication technologies, Information society. nologia cria parcialidade política, desfigurando o seu caráter de controle e regulação. Assim é que todos são unânimes em afirmar que neste momento não existe na Europa uma política de informação, e sim o desenvolvimento de planos e ações que refletem um imediatismo de respostas compulsivas à ditadura de um mundo regido pelo capital. Estes planos têm refletido o desconhecimento com o conteúdo, o lado imaterial da informação. É preciso, segundo nossos entrevistados, conhecer e estabelecer este conteúdo para então selecionar as tecnologias que a ele se adaptam e assim garantir a eficácia de uma educação e capacitação profissional que esta era exige e que parece ser muito mais complexa em exigências que a era industrial.

$\mathrm{Na}$ construção de uma política de informação para o Brasil e para que possamos por meio desta política ter voz ativa na construção da política de informação para o Mercosul, é importante que aprendamos com os erros e as dificuldades que a Europa vem enfrentando no setor e assim ganhar tempo, precisão e espaço na sociedade mundial da informação.

\section{NOTAS}

1. Yves Lasfargue - Diretor do Crefac (Centre de recherche et des Études Français pour l'accompagnement des changements) e diretor do Grupo de Alto Nível para a Construção da sociedade da informação.

2. Jean-Noël Tronc - Conselheiro técnico para as Tecnologias e sociedade da informação do Primeiro Ministro Francês, Lionel Jospin.

3. Phillippe Queau - Diretor da Unesco da Divisão de Informação e de Informática.

4. François Du Castel - Diretor da École supérieure de télécommunication; engenheiro geral de Telecomunicações e autor do livro Révolution Communicationnel.

5. Monique Dagnaud - Conselheira do CSA (Conseil Supérieur de l'Audiovisuel).

6. Serge Chambaud - Chefe do Departamento de Documentação e Informação do Inpi (Institut National de la Propriété Industrielle).

7. Daniel Confland - Diretor de Desenvolvimento da Société Jouve.

8. Jean-Michel Rauzier - Diretor da ADBS.

9. Yves Le Coadic - Professor de Informação e comunicação científica e técnica do CNAM (Conservatoire National des Arts et Métiers)

10. Serge Cacaly é diretor do CNRI (Centre National de Ressources Informationnels).

11. Centre Nacional de Ressources Informationnels.

12. Xavier Polanco. Responsável pelo setor de pesquisa e inovação do Inist (Institut National de l'information Scientifique et Technique).

13. Mission interministérielle de l'information scientifique et technique.

14. Direction des bibliothèques, des musées et de l'information scientifique et technique.

15. Délégation à I'Information Scientifique et Technique.
Marta Pinheiro Aun

(Professora da Escola de Biblioteconomia da UFMG; Doutoranda em Ciência da Informação convênio IBICT-CNPq/ECO-UFRJ); Bolsista da Capes.

E-mail: martaun@ez-bh.com.br 